\title{
Database on environmental conditions and biodiversity in shallow lakes in Belgium and the Netherlands
}

Pieter Lemmens (D) Aaike De Wever, Jochen Vandekerkhove, Koenraad Muylaert, Katleen Van der Gucht, Gabriel Zwart, Wouter Rommens, Jeroen Van Wichelen, Vanessa Geenens, Wim Vyverman, Luc Brendonck, Koen Martens, Steven A.J. Declerck \& Luc De Meester
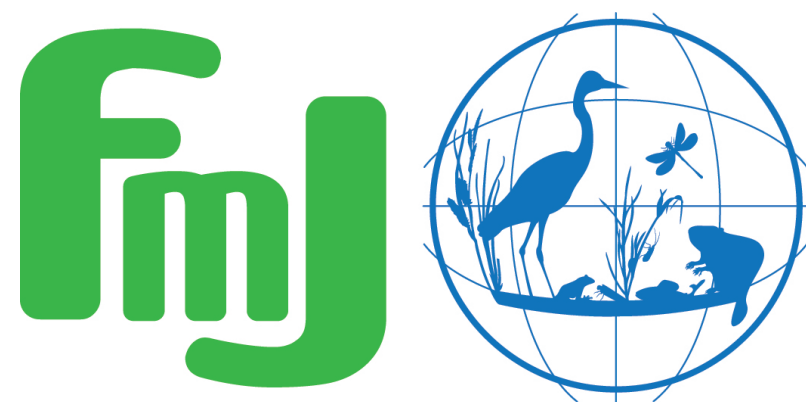

Freshwater Metadata Journal 



\title{
Database on environmental conditions and biodiversity in shallow lakes in Belgium and the Netherlands
}

\author{
Pieter Lemmens ${ }^{1}$ (iD , Aaike De Wever ${ }^{3}$, Jochen Vandekerkhove ${ }^{1}$, Koenraad Muylaert ${ }^{2}$, \\ Katleen Van der Gucht ${ }^{2}$, Gabriel Zwart ${ }^{4}$, Wouter Rommens ${ }^{1}$, Jeroen Van Wichelen ${ }^{2}$, \\ Vanessa Geenens ${ }^{2}$, Wim Vyverman ${ }^{2}$, Luc Brendonck ${ }^{1}$, Koen Martens ${ }^{3}$, Steven A.J. \\ Declerck $^{1}$ \& Luc De Meester ${ }^{1}$

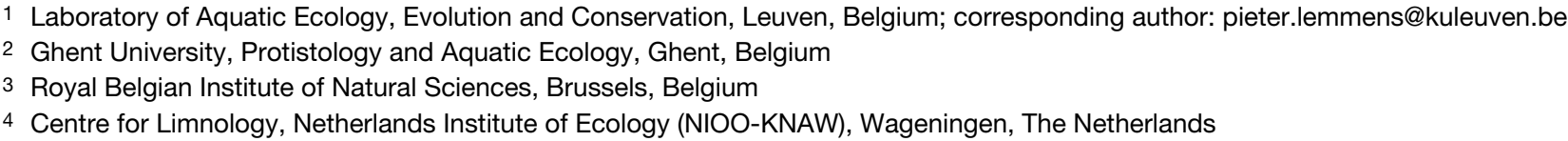

Please cite this paper as follows: Lemmens, P., De Wever, A., Vandekerkhove, J., Muylaert, K., Van der Gucht, K., Zwart, G., Rommens, W., Van Wichelen, J., Geenens, V., Vyverman, W., Brendonck, L., Martens, K., Declerck, S.A.J. \& De Meester, L., 2018. Database on environmental conditions and biodiversity in shallow lakes in Belgium and the Netherlands. Freshwater Metadata Journal 29: 1-9. https://doi.org/10.15504/fmj.2018.29

Received: 2018-01-15 / Published: 2018-08-17

\section{Keywords}

shallow lakes, Belgium, The Netherlands, plankton, fish, macrophytes, macro-invertebrates

\section{Short description of the dataset/summary}

The BIOMAN dataset comprises local environmental data and community data of different organism groups (bacterioplankton, zooplankton, ciliates, phytoplankton, macro-invertebrates, fish, protists and aquatic vegetation) from 98 shallow lakes covering three geographic regions in Europe sampled in 2000-2001. The database BIOMAN-Belgium is a subset of the overall BIOMAN dataset and includes data from 39 shallow lakes located in Belgium and the Netherlands.

\section{General information}

dataset entry ID:

name of the dataset:

full name of the dataset:

dataset short name:

type of dataset:

data type:
SF_23

BIOMAN-Belgium, biodiversity in shallow lakes in Belgium and the Netherlands BIOMAN-Belgium species (taxonomic group) per site database including environmental information point data/observation data 
science keywords according to GCMD:

topic: $\quad$ Biosphere, Biological Classification, Terrestrial Hydrosphere

ISO topic category according to ISO 19115:

Biota, Environment, Inland Waters

own science keywords:

shallow lakes, Belgium, the Netherlands, plankton, fish, macro-invertebrates, macrophytes

related project:

BIOMAN

funding:

The dataset generation was funded by the EU-project BIOMAN

(EVK2-CT-1999-00046).

\section{Technical and administrative specifications}

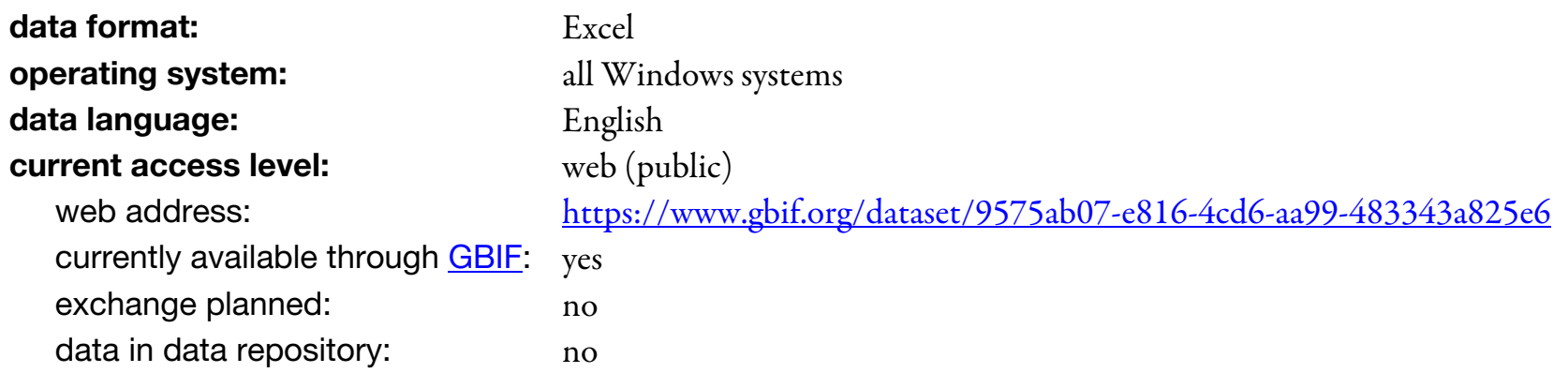

Do you plan to publish the data on the Freshwater Biodiversity Data Portal:

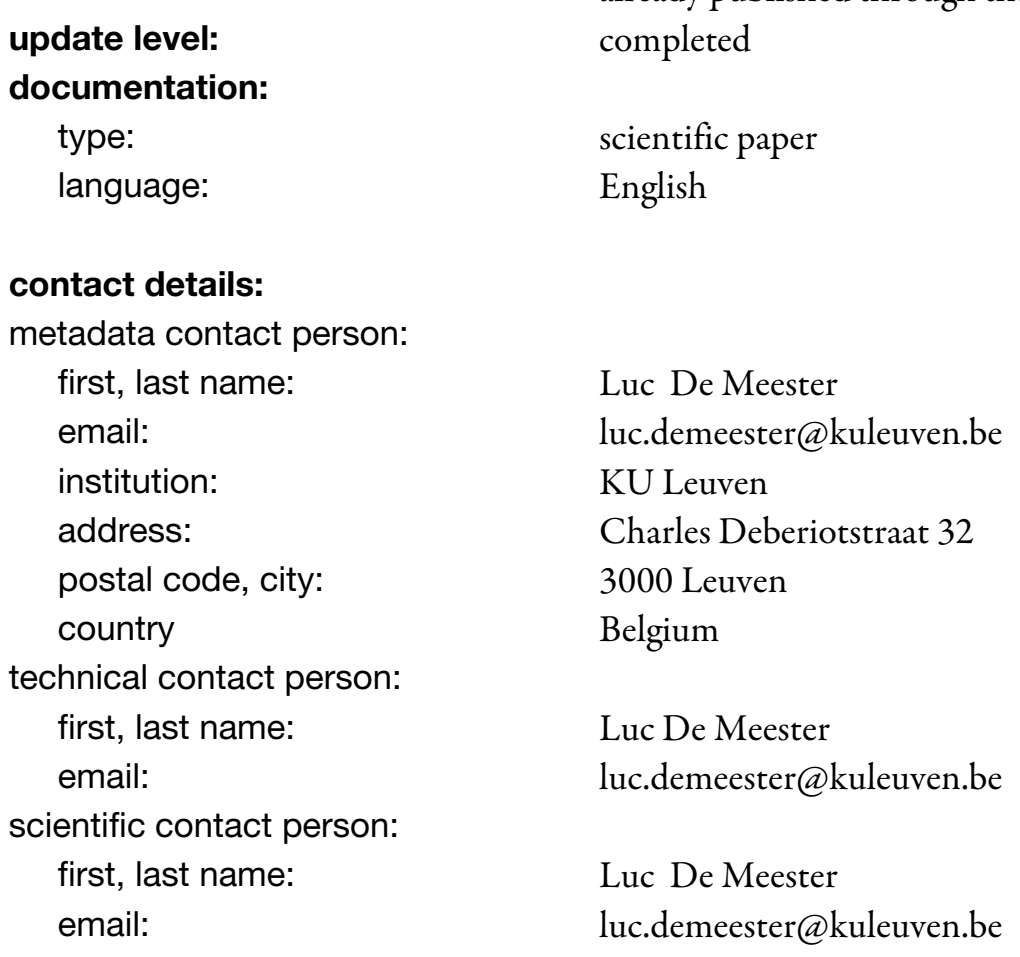

\section{Intellectual property rights and citation}

$\begin{array}{ll}\text { dataset publisher: } & \text { Pieter Lemmens } \\ \text { dataset creator (data compiler): } & \\ \text { contact name: } & \text { Pieter Lemmens }\end{array}$


contact email:

pieter.lemmens@kuleuven.be

contact institution:

KU Leuven

data contributors to/owners of this dataset:

number:

multiple

6

data contributor/owner 1:

contact name:

Steven Declerck

contact email:

s.declerck@nioo.knaw.nl

contact institute:

Centre for Limnology, Netherlands Institute of Ecology (NIOO-KNAW)

criteria for using this part of the dataset:

The dataset is publicly available (data portal, data archive) and can be used without restrictions, but dataset creator/data contributors must be informed prior to publication. Data must be acknowledged and cited correctly.

data contributor/owner 2:

contact name:

Wouter Rommens

contact email:

luc.demeester@kuleuven.be

contact institute:

KU Leuven

criteria for using this part of the dataset:

The dataset is publicly available (data portal, data archive) and can be used without restrictions, but dataset creator/data contributors must be informed prior to publication. Data must be acknowledged and cited correctly.

data contributor/owner 3:

contact name:

Koenraad Muylaert

contact email:

koenraad.muylaert@kuleuven.be

contact institute:

KU Leuven

criteria for using this part of the dataset:

The dataset is publicly available (data portal, data archive) and can be used without restrictions, but dataset creator/data contributors must be informed prior to publication. Data must be acknowledged and cited correctly.

data contributor/owner 4:

contact name:

Jochen Vandekerkhove

contact email:

luc.demeester@kuleuven.be

contact institute:

KU Leuven

criteria for using this part of the dataset:

The dataset is publicly available (data portal, data archive) and can be used without restrictions, but dataset creator/data contributors must be informed prior to publication. Data must be acknowledged and cited correctly.

data contributor/owner 5:

contact name:

Katleen Van der Gucht

contact email:

luc.demeester@kuleuven.be

contact institute:

criteria for using this part of the dataset:

Ghent University

The dataset is publicly available (data portal, data archive) and can be used without restrictions, but dataset creator/data contributors must be informed prior to publication. Data must be acknowledged and cited correctly.

data contributor/owner 6:

contact name:

contact email:

Gabriel Zwart

contact institute:

zwart@cl.nioo.knaw.nl

criteria for using this part of the dataset:

Centre for Limnology, Netherlands Institute of Ecology (NIOO-KNAW)

The dataset is publicly available (data portal, data archive) and can be used 
citation of this dataset:

author(s):

title and journal (name, number, pages):

year:

version:

doi:

citation of the metadata:

author(s):

title and journal (name, number, pages):

bioman_belgium, BioFresh. Sampling event dataset.

2018

1.3

https://doi.org/10.15468/duzvog

Lemmens P., De Wever A., Vandekerkhove J., Muylaert K., Van der Gucht K., Zwart G., Rommens W., Van Wichelen J., Geenens V., Vyverman W.,

Brendonck L., Martens K., Declerck S.A.J. \& De Meester L.

Database on environmental conditions and biodiversity in shallow lakes in

Belgium and the Netherlands. Freshwater Metadata Journal 29: 1-9

year:

2018

doi:

\section{dataset related references:}

reference 1:

author(s):

title:

year: https://doi.org/10.15504/fmj.2018.29

Declerck, S., Vandekerkhove, J., Johansson, L., Muylaert, K., Conde-Porcuna, J. M., Van der Gucht, K., Pérez-Martínez, C., Lauridsen, T., Schwenk, K., Zwart, G., Rommens, W., López-Ramos, J., Jeppesen, E., Vyverman, W., Brendonck L. $\&$ De Meester, L.

Multi-group biodiversity in shallow lakes along gradients of phosphorus and water plant cover. Ecology 86(7): 1905-1915.

2005

\section{General data specifications}

regional coverage of the dataset:

spatial extent of the dataset:

national

continents:

Europe

countries:

Europe: Belgium, Netherlands

world climatic regions according to Köppen:

Group C: temperate/mesothermal climates

freshwater ecoregions of the world (FEOW) according to WWF:

Europe: Central \& Western Europe

European ecoregions according to Illies (WFD):

Western Plains (ER13)

ecosystem type:

lakes/ponds

covered timeframe:

$2000-2001$

\section{Site specifications}

coordinate system/grid data:

datum (e.g. WGS84): latitude/longitude, format: DM

WGS84 
grid data available:

site coding:

site coding available:

number of digits:

example:

number of sites:

exact number of sites: no

yes, alphanumerical

4

GAV, KP

$<100$

39

\section{Climate and environmental data}

climate related data:
environmental data:

comments: no climate data available

no environmental data per catchment available

no environmental data per site avaiable

Data on land use around each lake was estimated as percentage coverage as described in:

Declerck, S., Vandekerkhove, J., Johansson, L., Muylaert, K., Conde-Porcuna, J. M., Van der Gucht, K., Pérez-Martínez, C., Lauridsen, T., Schwenk, K., Zwart, G., Rommens, W., López-Ramos, J., Jeppesen, E., Vyverman, W., Brendonck L. \& De Meester, L. (2005): Multi-group biodiversity in shallow lakes along gradients of phosphorus and water plant cover. Ecology 86(7): 1905-1915. total $\mathrm{P}$, ortho $\mathrm{P}$, nitrate, nitrite, total $\mathrm{N}$, water temperature, conductivity, chlorophyll, Secci disc depth, suspended solids

other physico-chemical parameters:

silica concentration

availability of physico-chemical data, if there is more than one sample per site: per sample

stressors influencing the sites: no stressor data available

reference sites available: no

\section{Biological data}

biological data origin:

from sampling,

BIOMAN

organism group addressed:

fish, macro-invertebrates (Mollusca, Crayfish, Ephemeroptera, Coleoptera, Trichoptera, Chironomidae), zooplankton, phytoplankton, macrophytes, other group(s): bacterioplankton, ciliates, protists

\section{Sample specifications/sample resolution}

\section{fish:}

sample information:

$\begin{array}{ll}\text { covered timeframe: } & 2000-2001 \\ \text { historical data: } & \text { no } \\ \text { palaeo data: } & \text { no } \\ \text { season: } & \text { autumn }\end{array}$


temporal resolution/frequency of sampling:

$$
\text { either in } 2000 \text { or in } 2001
$$

time series data:

no

comments:

Please refer to Declerck et al. (2005) for more details.

\section{taxonomic resolution:}

level:

species

comments:

Please refer to Declerck et al. (2005) for more details.

\section{taxonomic coding:}

reference(s):

Please refer to Declerck et al. (2005) for more details.

sample specifications:

type:

replicate samples:

quantitative (abundance data)

no

specification of method(s) used for sampling and sorting:

Please refer to Declerck et al. (2005) for more details.

reference(s):

Declerck, S., Vandekerkhove, J., Johansson, L., Muylaert, K., Conde-Porcuna, J. M., Van der Gucht, K., Pérez-Martínez, C., Lauridsen, T., Schwenk, K., Zwart, G., Rommens, W., López-Ramos, J., Jeppesen, E., Vyverman, W., Brendonck L. \& De Meester, L. (2005): Multi-group biodiversity in shallow lakes along gradients of phosphorus and water plant cover. Ecology 86(7): 1905-1915.

\section{macro-invertebrates:}

\section{sample information:}

covered timeframe:

$2000-2001$

historical data:

no

palaeo data:

no

season:

summer

temporal resolution/frequency of sampling:

either in 2000 or in 2001

time series data:

no

comments:

Please refer to Declerck et al. (2005) for more details.

\section{taxonomic resolution:}

level:

family

comments:

Please refer to Declerck et al. (2005) for more details.

\section{taxonomic coding:}

reference(s):

sample specifications:

type:

replicate samples:

number of samples:

Please refer to Declerck et al. (2005) for more details.

quantitative (abundance data)

no

39

specification of method(s) used for sampling and sorting:

Please refer to Declerck et al. (2005) for more details.

reference(s):

Declerck, S., Vandekerkhove, J., Johansson, L., Muylaert, K., Conde-Porcuna, J. M., Van der Gucht, K., Pérez-Martínez, C., Lauridsen, T., Schwenk, K., Zwart, G., Rommens, W., López-Ramos, J., Jeppesen, E., Vyverman, W., Brendonck L. \& De Meester, L. (2005): Multi-group biodiversity in shallow lakes along gradients of phosphorus and water plant cover. Ecology 86(7): 1905-1915.

\section{zooplankton:}

\section{sample information:}

covered timeframe:

$2000-2001$

historical data:

no

palaeo data:

no 
season: spring, summer, autumn

temporal resolution/frequency of sampling:

monthly either in 2000 or in 2001; samples from different sampling occasions were pooled

time series data:

no

comments:

Please refer to Declerck et al. (2005) for more details.

\section{taxonomic resolution:}

level: $\quad$ species

percentage of species level data: 100

comments:

taxonomic coding:

reference(s):

Please refer to Declerck et al. (2005) for more details.

Please refer to Declerck et al. (2005) for more details.

\section{sample specifications:}

type:

quantitative (abundance data)

replicate samples:

no

number of samples:

39

specification of method(s) used for sampling and sorting:

Please refer to Declerck et al. (2005) for more details.

reference(s):

Declerck, S., Vandekerkhove, J., Johansson, L., Muylaert, K., Conde-Porcuna, J. M., Van der Gucht, K., Pérez-Martínez, C., Lauridsen, T., Schwenk, K., Zwart, G., Rommens, W., López-Ramos, J., Jeppesen, E., Vyverman, W., Brendonck L. \& De Meester, L. (2005): Multi-group biodiversity in shallow lakes along gradients of phosphorus and water plant cover. Ecology 86(7): 1905-1915.

\section{phytoplankton: \\ sample information:}

covered timeframe: $\quad 2000-2001$

historical data: no

season: $\quad$ spring, summer, autumn

temporal resolution/frequency of sampling:

monthly during the growing season (May-October) either in 2000 or 2001;

samples from different sampling occasions were pooled

comments: $\quad$ Please refer to Declerck et al. (2005) for more details.

\section{taxonomic resolution:}

level:

taxonomic coding:

reference(s):

sample specifications:

type:

replicate samples:

number of samples:

genus

Please refer to Declerck et al. (2005) for more details.

quantitative (abundance data)

no

39

specification of method(s) used for sampling and sorting:

Please refer to Declerck et al. (2005) for more details.

reference(s):

Declerck, S., Vandekerkhove, J., Johansson, L., Muylaert, K., Conde-Porcuna, J. M., Van der Gucht, K., Pérez-Martínez, C., Lauridsen, T., Schwenk, K., Zwart, G., Rommens, W., López-Ramos, J., Jeppesen, E., Vyverman, W., Brendonck L. \& De Meester, L. (2005): Multi-group biodiversity in shallow lakes along gradients of phosphorus and water plant cover. Ecology 86(7): 1905-1915.

\section{macrophytes:}


$\begin{array}{ll}\text { historical data: } & \text { no } \\ \text { palaeo data: } & \text { no } \\ \text { season: } & \text { summer }\end{array}$

temporal resolution/frequency of sampling:

comments: $\quad$ Please refer to Declerck et al. (2005) for more details.

\section{taxonomic resolution:}

level: $\quad$ species

percentage of species level data: 100

comments:

Please refer to Declerck et al. (2005) for more details.

taxonomic coding:

reference(s):

Please refer to Declerck et al. (2005) for more details.

\section{sample specifications:}

type: $\quad$ quantitative (abundance data)

replicate samples: no

number of samples: $\quad 39$

specification of method(s) used for sampling and sorting:

Please refer to Declerck et al. (2005) for more details.

reference(s): $\quad$ Declerck, S., Vandekerkhove, J., Johansson, L., Muylaert, K., Conde-Porcuna, J. M., Van der Gucht, K., Pérez-Martínez, C., Lauridsen, T., Schwenk, K., Zwart, G., Rommens, W., López-Ramos, J., Jeppesen, E., Vyverman, W., Brendonck L. \& De Meester, L. (2005): Multi-group biodiversity in shallow lakes along

\section{other group(s):} gradients of phosphorus and water plant cover. Ecology 86(7): 1905-1915.

\section{sample information:}

covered timeframe: $\quad 2000-2001$

historical data: no

season: $\quad$ spring, summer, autumn

temporal resolution/frequency of sampling:

time series data:

comments: $\quad$ Please refer to Declerck et al. (2005) for more details.

\section{taxonomic resolution:}

level:

other taxonomic levels: $\quad$ protists \& bacteria: DGGE, ciliates: species level

comments:

\section{taxonomic coding:}

reference(s):

Please refer to Declerck et al. (2005) for more details.

sample specifications:

type:

Please refer to Declerck et al. (2005) for more details.

replicate samples:

quantitative (abundance data)

no

specification of method(s) used for sampling and sorting:

Please refer to Declerck et al. (2005) for more details.

reference(s):

Declerck, S., Vandekerkhove, J., Johansson, L., Muylaert, K., Conde-Porcuna, J. M., Van der Gucht, K., Pérez-Martínez, C., Lauridsen, T., Schwenk, K., Zwart, G., Rommens, W., López-Ramos, J., Jeppesen, E., Vyverman, W., Brendonck L. \& De Meester, L. (2005): Multi-group biodiversity in shallow lakes along gradients of phosphorus and water plant cover. Ecology 86(7): 1905-1915. 


\section{Other specifications}

\section{availability of photos: no \\ availability of maps: no \\ quality control procedures:}

Were any quality control procedures applied to your dataset?

yes

quality control protocols and comments:

Species names were checked using the GBIF species list.

\section{Acknowledgements}

The BIOMAN database has been collected as part of the EU funded BIOMAN project (EVK-CT-1999-00046). The authors acknowledge the funding of the SAFRED project (Saving freshwater biodiversity research data - 2015-2018) that allowed processing and publishing the BIOMAN data, amongst others.

\section{References}

Declerck, S., Vandekerkhove, J., Johansson, L., Muylaert, K., Conde-Porcuna, J. M., Van der Gucht, K., Pérez-Martínez, C., Lauridsen, T., Schwenk, K., Zwart, G., Rommens, W., López-Ramos, J., Jeppesen, E., Vyverman, W., Brendonck, L. \& De Meester, L., 2005. Multi-group biodiversity in shallow lakes along gradients of phosphorus and water plant cover. Ecology 86(7): 1905-1915 